\title{
Objetivos de Desenvolvimento Sustentá- vel: os impactos do combate à corrupção para afirmação da Agenda 2030 da ONU à luz da Teoria do Desenvolvimento como Liberdade de Amartya Sen
}

\author{
Sustainable Development Goals: the impacts \\ of anticorruption measures for the UN 2030 \\ Agenda establishment in light of Amartya Sen's \\ Development as Freedom Theory
}

\author{
Adriana da Costa Ricardo Schier ${ }^{1}$ \\ Mirela Miró Ziliotto
}

1 Doutora em Direito pela Universidade Federal do Paraná (2009). PósDoutora em Direito Público pela PUC-PR (2018). Professora de Direito Administrativo do Centro Universitário Autônomo do Brasil - UniBrasil - na Graduação, no Mestrado e Doutorado em Direito e do Instituto de Direito Romeu Felipe Bacellar - Curso de Pós-Graduação em Direito Administrativo. Vice-Presidente do Instituto Paranaense de Direito Administrativo. Atualmente é consultora para assuntos da Administração Tributária de diversos Sindicatos Nacionais e Regionais, especialmente para assuntos da Lei Orgânica da Administração Tributária.

2 Mestranda em Direito Econômico e Desenvolvimento pela Pontifícia Universidade Católica do Paraná - PUC/PR. Especialista em Direito Administrativo Aplicado pelo Instituto Romeu Felipe Bacellar Filho (2018). Graduada em Direito pela Universidade Positivo (2016). Tem experiência na área de Direito, com ênfase em Direito Administrativo e Constitucional, atuando principalmente na área de licitações e contratos, processos administrativos disciplinares e processos de responsabilização por improbidade administrativa. 
Resumo: O presente estudo objetiva discutir os impactos do combate à corrupção no Brasil para a afirmação da Agenda 2030 da ONU, à luz da Teoria do Desenvolvimento como Liberdade de Amartya Sen, especialmente em relação à influência da liberdade instrumental da garantia de transparência nos padrões de comportamento dos indivíduos. Para tanto, pelo método hipotético-dedutivo, em um primeiro momento analisou-se a Teoria de Desenvolvimento de Amartya Sen propriamente dita, para, na sequência, avaliar a sua relação com os Objetivos de Desenvolvimento Sustentável da Agenda 2030, tecendo comentários acerca da importância da confiança nas instituições e dos impactos do combate à corrupção para efetivação daqueles objetivos. Ao final, foram apresentadas as conclusões, demonstrando-se que o combate à corrupção previsto na meta 16.5 da Agenda 2030 permite a efetivação e cumprimento de outros ODS, pois o comportamento íntegro, penetrando na essência das instituições, interferindo nos seus hábitos, costumes, valores, práticas e processos, altera a cultura da corrupção para uma cultura da ética, integridade e transparência, permitindo melhoria na alocação do dinheiro público e na qualidade dos serviços prestados, e, por conseguinte, direcionando o Brasil ao desenvolvimento nacional sustentável.

Palavras-chave: Desenvolvimento como Liberdade. Garantias de Transparência. Códigos de Comportamento. Objetivos de Desenvolvimento Sustentável. Corrupção.

Abstract: The present study aims to discuss the fight against corruption in Brazil and its impact on the UN 2030 Agenda affirmation, under Amartya Sen's Development as Freedom Theory, especially aspects related to the way transparency guarantees 
influences individuals' behavior patterns. Therefore, using the hypothetical-deductive method, at first, the Amartya Sen Development Theory was analyzed in order to subsequently assess its relationship with the Sustainable Development Goals Agenda, discussing the importance of institutional accountability and the effects of anti-corruption practices to achieve those goals. In the end, the conclusions were presented, demonstrating how tackling corruption, foreseen in 2030 Agenda goal 16.5, allows other objectives' fulfillment, such as integrity behavior, penetrating the essence of the institutions, interfering in their habits, customs, values, practices, and processes, alters the corruption culture to an ethic, integrity and transparency one. Consequently, they offer an improvement in public resources' allocation and in the provided services' quality thus leading Brazil to sustainable development.

Keywords: Development as Freedom. Transparency Guarantees. Behavior Codes. Sustainable Development Goals. Corruption.

\section{Introdução}

A influência dos valores prevalecentes em uma instituição, seja ela pública ou privada, é importante ferramenta para mensurar a existência ou não de corrupção. Essa influência, entretanto, não se trata de uma descoberta recente, é algo antigo, que remonta aos filósofos do período clássico da Grécia antiga, mas que, sem dúvidas, afeta sobremaneira a efetividade dos Objetivos de Desenvolvimento Sustentável - ODSs da Agenda 2030 da Organização das Nações Unidas - ONU. Isso porque, ao se pensar que a confiança nas instituições e o comprometimento em prol do combate à 
corrupção e em favor da atuação ética, íntegra e transparente é pilar fundamental à efetividade dos ODSs, pois sem esse comprometimento não haverá sucesso em qualquer estrutura mínima organizacional, quiçá em um país como o Brasil.

Dessa forma, é imprescindível que as organizações se preocupem com a efetivação dos ODSs, demonstrando, na prática, o engajamento dos indivíduos ocupantes de cargos de alto escalão - seja na iniciativa privada, seja no setor público, e, principalmente, em âmbito político -, tendo em vista que, após o conhecimento, a compreensão e a capacitação em relação às políticas adotadas para o combate à corrupção, comportamentos similares poderão ser replicados pelos demais indivíduos, conforme "efeito manada".

Nesse sentido, países que buscam efetivar a Agenda 2030 da ONU devem prezar por líderes conectados e engajados com a pauta da ética e da integridade. Do contrário, não haverá confiança nas instituições e tampouco mudança de cultura dentro da sociedade, e, por conseguinte, os reflexos decorrentes das práticas de corrupção consolidar-se-ão como uma das mais graves barreiras no caminho do desenvolvimento.

Diante desse cenário, a problemática do presente artigo abrange, justamente, a análise da importância da instituição de códigos de comportamento pautados pela integridade, conformidade, ética e transparência como instrumentos de efetivação da confiança nas instituições e de afirmação da Agenda 2030 no Brasil, tendo em vista os severos prejuízos causados ao desenvolvimento nacional sustentável por práticas ilícitas, ilegítimas e ilegais.

Assim, considerando-se a relevância e a complexidade atual do tema, a partir do método hipotético-dedutivo, o presente estudo objetiva discutir os impactos do combate à corrupção no Brasil para a afirmação da Agenda 2030 da 
ONU, à luz da Teoria do Desenvolvimento como Liberdade de Amartya Sen, especialmente em relação à influência da liberdade instrumental da garantia de transparência nos padrões de comportamento dos indivíduos. Para tanto, em um primeiro momento, realizou-se estudo propriamente dito da Teoria de Desenvolvimento de Amartya Sen, e, na sequência, analisou-se a sua relação com os Objetivos de Desenvolvimento Sustentável da Agenda 2030, tecendo comentários acerca da importância da confiança nas instituições e dos impactos do combate à corrupção para efetivação daqueles objetivos. Ao final, foram apresentadas as conclusões, demonstrando-se que o combate à corrupção previsto na meta 16.5 da Agenda 2030 permite a efetivação e cumprimento de outros objetivos, pois o comportamento íntegro, penetrando na essência das instituições, interferindo nos seus hábitos, costumes, valores, práticas e processos, permite a substituição da cultura da corrupção por uma cultura da ética, integridade e transparência, permitindo melhoria na alocação do dinheiro público e na qualidade dos serviços prestados. Centrada a análise na esfera nacional, conclui-se que tal prática permitirá o direcionamento do Brasil ao desenvolvimento nacional sustentável.

\section{O desenvolvimento como liberdade para Amartya Sen}

A Teoria do Desenvolvimento como Liberdade de Amartya Sen objetiva demonstrar que o desenvolvimento, em contraste com visões mais restritas sobre o mesmo, que o identificam como crescimento econômico, aumento de renda, industrialização, avanço tecnológico ou modernização social, deve, a bem da verdade, ser avaliado como um processo de expansão de liberdades reais onde os indivíduos são capazes 
de desfrutar, o modo de vida que valorizam. ${ }^{3} \mathrm{O}$ economista adota, nesses termos, uma vertente da avaliação das liberdades não apenas como fins primordiais do desenvolvimento, mas também como os principais meios, elencando-se cinco liberdades instrumentais que auxiliam na promoção das capacidades gerais de uma pessoa, sendo elas: (1) liberdades políticas, (2) facilidades econômicas, (3) oportunidades sociais, (4) garantias de transparência e (5) segurança protetora. ${ }^{4}$

Diante da delimitação temática proposta na introdução, a análise do presente estudo ficará restrita às liberdades relacionadas às garantias de transparência. Essas, para Amartya Sen, destacam-se nas interações sociais, onde os indivíduos interagem uns com os outros com um nível de presunção básico de confiança em relação ao que lhes é oferecido e o que podem obter. É o que o autor chama de "liberdade de lidar uns com os outros sob garantias de divulgação e clareza." ${ }^{5}$ Quando essa confiança é abalada, portanto, o nível de presunção é afetado, o que facilita a prática de condutas ilícitas e fraudulentas, aumentando a assimetria de informação. É dizer, quando as instituições não são capazes de demonstrar o universalismo, a imparcialidade, a justeza e a probidade

3 Tradução literal de: “Development can be seen, it is argued here, as a process of expanding the real freedoms that people enjoy. Focusing on human freedoms contrasts with narrower views of development, such as identifying development with the growth of gross national product, or with the rise in personal incomes, or with industrialization, or with technological advance, or with social modernization." SEN, 2000, p. 3 e 11.

4 Tradução literal de: "Five distinct types of freedom, seen an "instrumental" perspective, are particularly investigated in the empirical studies that follow. These include (I) political freedoms, (2) economic facilities, (3) social opportunities, (4) transparency guarantees and (5) protective security." SEN, 2000, p. 11.

5 Tradução literal de: “Transparency guarantees deal with the need for openness that people can expect: the freedom to deal with one another under guarantees of disclosure and lucidity." SEN, 2000, p. 39. 
de seus procedimentos, não há apoio, solidariedade e confiança dos cidadãos, abrindo-se ala para práticas corruptas. Por conseguinte, há prejuízos às instituições, notadamente em relação a sua credibilidade, à confiança social e à própria Democracia. $^{6}$

É por isso que, para Amartya Sen, as garantias de transparência possuem um papel instrumental importante para inibir a corrupção. ${ }^{7} \mathrm{O}$ que é especialmente importante em sistemas capitalistas, já que os valores possuem um papel de extrema relevância nos mesmos. Daí se afirmar que o funcionamento do mercado, embora muitas vezes visto como mecanismo pautado apenas pela ganância dos indivíduos, na verdade, para ser bem sucedido, necessita de instituições sólidas. Elas precisam assegurar as relações, bem como a ética ${ }^{8}$ no comportamento daqueles que se relacionam, utilizando-se a confiança na palavra e a promessa das partes envolvidas como pilares fundamentais da estrutura. ${ }^{9}$ Nesse sentido, portanto, Amartya Sen destaca que "as instituições baseadas em ajustes entre indivíduos operam com base em padrões de comportamento comuns, confiança mútua e segurança em relação à ética da outra parte".$^{10}$

6 FOCKINK, 2019, p. 191.

7 Tradução literal de: "These guarantees have a clear instrumental role in preventing corruption, financial irresponsibility and underhand dealings." SEN, 2000, p. 40.

8 Não se olvida o posicionamento de Amartya Sen quando afirma que a ética capitalista é limitada em aspectos como desigualdade econômica e proteção ambiental, de modo que o presente estudo busca alertar a necessidade da presença de valores éticos nas relações entre as partes para que exista um mercado bem sucedido.

9 SEN, 2000, p. 262.

10 Tradução literal de: "since institutions based on interpersonal arrangements and shared understandings operate on the basis of common behavior patterns, mutual trust and confidence in the other party's ethics." SEN, 2000, p. 268. 
Assim, para além das virtudes de um comportamento prudente, deve-se atentar à formação e manutenção da confiança para resistir às tentações da corrupção disseminada. Isso porque um dos problemas mais destacados relacionados aos códigos de comportamento, segundo o economista, é a corrupção econômica e a sua relação com o crime organizado, ${ }^{11}$ onde falta, justamente, a confiança e a honra para o cumprimento do que foi combinado. $\mathrm{Ou}$ seja, há um ambiente sem confiança mútua e sem senso de obrigação tácito. E, sem confiança, fazendo uso novamente das palavras de Caroline Fockink, não há credibilidade nas instituições, na confiança social e na própria Democracia. ${ }^{12}$

No Brasil, são crescentes os casos desvelados de corrupção em razão da desconfiança generalizada. Entretanto, ainda não houve na população a mobilização ou a mudança de comportamento necessárias para a transformação desse cenário, dado que o grande desafio consiste, justamente, em buscar mecanismos capazes de mudar a cultura cotidiana e endêmica da corrupção hoje pautada, especialmente, pela falta de confiança e transparência. ${ }^{13} \mathrm{E}$, segundo já destacado, a confiança nas instituições deve ser considerada elemento fundamental dentro de uma sociedade, o que depende, senão, da coerência e compatibilidade do funcionamento daquelas com os motivos que justificam a sua existência, ${ }^{14}$ bem como com os valores por elas externados. Não sem razão, se o Estado for cúmplice de práticas corruptas, o resultado será a existência de instituições democráticas frágeis, decorrentes da falta de credibilidade dos cidadãos na capacidade daquele

11 SEN, 2000, p. 266-268.

12 FOCKINK, 2019, p. 191.

13 COSTA, 2013, p. 18.

14 FOCKINK, 2019, p. 184 e 186. 
de governar de forma imparcial e eficiente, ${ }^{15}$ conforme será analisado no item a seguir.

\subsection{A influência dos valores nas liberdades des- frutadas}

O agir humano decorre de valores, que são os critérios utilizados nas escolhas que representam as preferências de cada indivíduo. ${ }^{16}$ Em outras palavras, são dispositivos de análise de percepções que influenciam o que se vê no ambiente e as decisões comportamentais tomadas ${ }^{17} \mathrm{~A}$ influência dos valores nos códigos de comportamento, entretanto, não se trata de objeto de discussões recentes; é tema que remonta aos filósofos do período clássico da Grécia Antiga, quando das discussões sobre justiça. ${ }^{18}$ Os valores, por assim dizer, guiam as ações humanas, transmitindo padrões gerais de orientação aos indivíduos, o que, no âmbito das instituições, não é diferente, pois os valores institucionais são aqueles que demonstram "as crenças básicas de uma organização e exibem a essência de sua filosofia para o alcance do sucesso,

15 Tradução literal de "if the State apparatus is complicit (passively or actively) in these practices (this also being a violation of human rights, starting with the principle of non-discrimination), the result will be fragile democratic institutions caused by citizens losing faith in the ability of the latter to govern the territorial community impartially and efficiently." PARISI, 2019, p. 400-401.

16 ZENKNER, 2019, p. 31.

17 RAVLIN, 2003, p. 1402.

18 Sobre o tema cf. diálogo do Livro II, sobre justiça: "de maneira que, quando as pessoas praticam ou sofrem injustiças uma das outras, e provam de ambas, lhes parece vantajoso, quando não podem evitar uma coisa ou alcançar a outra, chegar a um acordo mútuo, para não cometerem injustiças nem serem vítimas delas. Daí se originou o estabelecimento de leis e convenções entre elas e a designação de legal e justo para as prescrições da lei." PLATÃO, 2006, p. 45. 
uma vez que fornecem uma direção comum e orientam o comportamento cotidiano."19

Para Amartya Sen, os valores que influenciam os indivíduos podem emergir de diferentes situações. ${ }^{20}$ Primeiro, podem decorrer de uma reflexão e análise sobre preocupações, responsabilidades ou apenas como efeitos do bom comportamento (escolha reflexiva). Segundo, os valores podem provir da observação das convenções e costumes estabelecidos (comportamento concordante). Terceiro, os valores podem advir de discussões públicas. Por fim, eles podem ser determinados pela seleção evolutiva. Por essa razão, os valores são tão importantes para a compreensão do comportamento humano, integrando, de fato, os códigos de comportamento.

Valores como a ética, por exemplo, envolvem regras de comportamento em torno daquilo que é certo e errado, bem como estabelecem um código de conduta visando o bem comum. ${ }^{21}$ Em se tratando de ética pública, esta diz respeito às ações de agentes públicos pautadas pela disciplina, honra, imparcialidade e pelo exercício exclusivo da comunidade, ou seja, como o conjunto de princípios e regras de comportamento correto na administração pública. ${ }^{22}$ Daí porque se afirmar que a confiança é o que levará a um bom convívio social, sendo o respeito e a confiança no outro e nas instituições o alicerce da cooperação entre os indivíduos em prol do bem

19 CUNHA, 2016, p. 19.

20 SEN, 2000, p. 348-349.

21 ZENKNER, 2019, p. 32.

22 Tradução literal de "Con l'espressione "etica pubblica" si intende l'agire da parte di ogni pubblico agente, nell'esercizio delle funzioni che gli sono affidate, con disciplina ed onore, con imparzialità nei confronti del pubblico e attraverso una azione che nel suo complesso si ponga al servizio esclusivo della Nazione, cioè della collettività medesima. (...) La definizione dell'etica pubblica (o etica nel servizio pubblico) come l'insieme dei principi e delle norme di comportamento corretto in seno all'amministrazione pubblica (...)." COLAPINTO, 2019, p. 207, 209-210. 
de todos. Assim, uma vez mais se destaca que a confiança nas instituições depende da sua compatibilidade com a probidade, eficiência e honestidade para com o objetivo pelo qual elas foram legalmente criadas. ${ }^{23}$ Do contrário, como assevera Marcelo Zenkner, “a percepção de que os outros são desonestos e de que a lei é leniente acaba gerando uma desconfiança generalizada que facilita o descumprimento de normas estabelecidas, já que as pessoas são induzidas a comportamentos semelhantes àqueles que estão ao seu redor." 24 Trata-se do efeito manada: havendo uma percepção objetiva de um indivíduo acerca da prevalência ou não da corrupção em uma determinada sociedade, os indivíduos "tendem a alinhar seu comportamento com aquele grupo que o cerca." 25

A abordagem das liberdades como instrumentos ao desenvolvimento, portanto, permite reconhecer o papel de influência dos valores sociais e costumes nas liberdades que os indivíduos desfrutam e prezam. Segundo Amartya Sen, normas comuns podem influenciar diversas características sociais como a igualdade entre os sexos, o padrão das famílias e o cuidado com o meio ambiente. Por essa razão, por exemplo, os valores e costumes sociais prevalecentes podem indicar a presença ou não de corrupção em determinadas sociedades. ${ }^{26}$ Para o economista, o exercício da liberdade é mediado por valores, que, por sua vez, são influenciados por discussões públicas e interações sociais, propriamente influenciadas pelas liberdades de participação. ${ }^{27} \mathrm{~A}$ partir daí, portanto, pode-se afirmar que o aumento de liberda-

23 FOCKINK, 2019, p. 186.

24 ZENKNER, 2019, p. 37-38.

25 CANETTI, 2019, p. 115.

26 SEN, 2000, p. 9.

27 ZENKNER, 2019, p. 23 e 24. 
des permite a existência de "uma cidadania que preconize, sobretudo, a participação ativa dos cidadãos na tomada de decisões", ampliando e diversificando o cenário político, $\mathrm{e}$, por conseguinte, aumentando a agenda do Estado. ${ }^{28} \mathrm{~A}$ corrupção, entretanto, é, senão, um exemplo de inversão de valores para ampliação de liberdade, já que rompe com pressupostos fundamentais do regime democrático, reduz a influência da população nas decisões políticas e minimiza a transparência das ações governamentais. ${ }^{29}$ Daí se dizer que a corrupção, a bem da verdade, "dissemina o descrédito nas instituições públicas e privadas, subverte acordos de lealdade, fragiliza regras de confiança social e vilipendia o mérito".$^{30}$ Ou seja, a corrupção é percebida como uma prática capaz de comprometer alguns dos princípios básicos da estabilidade de um sistema político, como a busca pela paz, a manutenção e o fortalecimento do Estado de Direito, a democracia, o respeito ao princípio da liberdade e os direitos humanos fundamentais. ${ }^{31}$

O comportamento social, portanto, sempre será determinado por valores, princípios, normas de conduta e padrões de comportamento existentes. ${ }^{32}$ Assim, a mudança de determinado padrão de comportamento de uma organização será um importante instrumento de autoconhecimento e aculturamento para uma realidade da integridade, conformidade, ética e transparência, já que, conforme destacado, o modo como os indivíduos se comportam é reflexo do que eles veem e percebem em outros indivíduos. ${ }^{33}$ Assim, se o

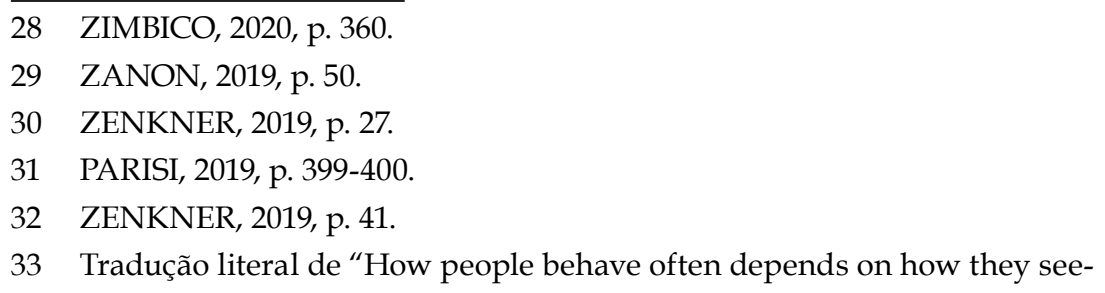

33 Tradução literal de "How people behave often depends on how they see- 
que move a sociedade são os valores nela inseridos, se a incorreção em determinada comunidade for aceitável, aqueles que a integram serão mais propensos à desonestidade. ${ }^{34} \mathrm{Da}$ mesma forma, indivíduos que atuam com integridade, nem sempre, necessariamente, sentirão a decência da probidade de sua conduta, sendo que podem agir, meramente, em razão de condutas de comportamento estabelecidas pelo comportamento de outros indivíduos. ${ }^{35}$ Assim, no mesmo sentido que a presença de comportamento corrupto encoraja outros comportamentos corruptos, a diminuição do predomínio da corrupção pode enfraquecê-la ainda mais, de modo que, a inversão de direção desse círculo vicioso implicará a existência de um círculo virtuoso. ${ }^{36}$

$E$ a integridade, que pode ser considerada o oposto da corrupção, permite maior confiança entre os indivíduos, já que traz consigo o valor da lealdade, ${ }^{37}$ o que, por conseguinte, amplia as liberdades, considerando-se, especialmente, as garantias de transparência. Um exemplo bastante conhecido e que retrata a discussão da ausência de confiança e transparência em sociedades é o "jeitinho brasileiro". ${ }^{38}$ Como bem destaca Keith Rosenn, o "jeito" é mais fácil de descrever do

and perceive others as be having. Much depends, therefore, on the reading of prevailing behavioral norms." SEN, 2000, p. 277.

34 RESENDE, 2015.

35 "Many men behave very decently, and through the whole of their lives avoid any considerable degree of blame, who yet, perhaps, never felt the sentiment upon the propriety of which we found our approbation of their conduct, but acted merely from a regard to what they saw were the established rules of behavior." SMITH, 1970, p. 143.

36 Tradução literal de "Just as the presence of corrupt behavior encourages other corrupt behavior, the diminution of the hold of corruption can weaken it further. In trying to alter a climate of conduct, it is encouraging to bear in mind the fact that each vicious circle entails a virtuous circle if the direction is reversed." SEN, 2000, p. 278.

37 ZENKNER, 2019, p. 49.

38 HOLANDA, 1995, p. 139. 
que de definir, ${ }^{39}$ e trata-se de um valor da sociedade brasileira que significa uma forma de expressar condutas realizadas para contornar de forma ilícita, ilegal ou ilegítima uma situação. ${ }^{40}$ Ocorre que essa prática é, ao mesmo tempo, fator que gera e produz desconfiança, retratando o círculo vicioso destacado por Amartya Sen. Como exemplo, o "jeitinho brasileiro" se apresenta naquela situação típica em que, em uma estrada, dois veículos transitando em sentido contrário se cruzam e um deles dá sinais de luz constantemente; tal ação busca demonstrar que existem policiais na pista, alertando-se o outro motorista para que não seja multado. A ideia aqui retratada, portanto, é de que "um motorista adverte o outro sobre a polícia e frauda a fiscalização porque ele não confia nos policiais, ou seja, comete uma pequena corrupção para evitar ser vítima de outra." 41

Diante desse cenário, é possível perceber que a ausência de confiança abre espaço à corrupção, minimizando a transparência das ações governamentais - seja em razão das fraudes nos processos eleitorais, da desconfiança ou da suspeita gerada entre os próprios cidadãos em relação ao governo - ${ }^{42}$ afetando, sobremaneira, a garantia da transparência

39 Segundo o autor o jeito pode ser definido ao menos em cinco tipos de comportamentos: “1) o servidor deixa de cumprir seu dever legal em troca de vantagens pecuniárias ou promoções funcionais (...); 2) o particular que emprega um subterfúgio para frustrar a prestação de uma obrigação legal sensata e justa (...);3) o funcionário público que cumpre suas funções com rapidez somente mediante vantagens pecuniárias ou promessa de promoção (...); 4) o particular que burla uma lei irrealista, injusta ou economicamente ineficiente (...); e 5) o servidor público que foge do cumprimento de seu dever legal em razão de sua convicção de que a lei é irrealista, injusta ou economicamente ineficiente (...)." ROSENN, 1998, p. 13-14.

40 ALMEIDA, 2007, p. 17.

41 ZENKNER, 2019, p. 68.

42 ZANON, 2019, p. 51. 
e, por conseguinte, reduzindo as liberdades para ampliação das capacidades.

São inúmeros e óbvios, portanto, os problemas decorrentes do componente da corrupção inserido no “jeitinho brasileiro", especialmente a perda da credibilidade governamental, de modo que "o poder de governo para promover o desenvolvimento é enfraquecido à medida em que a tolerância à corrupção abate o apoio popular e o respeito pelo governo", retardando-se a eficiência da administração pública. ${ }^{43}$ Assim, não restam dúvidas de que a corrupção é uma forma de exercer influência ilícita, ilegal e ilegítima, ${ }^{44}$ reconhecida como um "fenômeno social desviante", ${ }^{45}$ cujos reflexos são incalculáveis, sobretudo se considerar que a prevalência de condutas corruptas em uma determinada sociedade é uma das mais graves barreiras no caminho do desenvolvimento. Um nível elevado de corrupção em um determinado país, por exemplo, pode tornar ineficazes as políticas públicas propostas, bem como afastar o investimento das atividades econômicas de setores produtivos. ${ }^{46}$ Não sem razão, o Escritório das Nações Unidas sobre Drogas e Crimes destaca que nos países desenvolvidos, nos serviços de saúde, estima-se que condutas corruptas como fraude e abuso custam entre US\$12 e US\$ 23 bilhões por ano a cada governo. ${ }^{47}$ Da mesma forma, o Fórum Econômico Mundial

43 ROSENN, 1998, p. 97, 98, 100 e 103.

44 BOBBIO; MATTEUCCI; PASQUINO, 2000, p. 292.

45 Tradução literal de "deviant social phenomenon". PARISI, 2019, p. 404.

46 Tradução literal de: "A high level of corruption can make public policies ineffective and can also draw investment and economic activities away from productive pursuits toward the towering rewards of underhanded activities." SEN, 2000, p. 275.

Sobre o tema, conferir a análise realizada na dissertação de mestrado de Flavius Raymundo Arruda Sodré, 2014.

UNODC, 2015, p. 4. 
avalia que o custo da atividade econômica é acrescido em até $10 \%$ em média em razão de práticas corruptas. ${ }^{48}$

É necessária, portanto, a realização de uma abordagem cultural que demonstre efetivamente os custos da corrupção, bem como que implemente uma consciência da extensão repreensível das fraudes e ilícitos de corrupção. ${ }^{49}$ Assim, ao se chegar a um consenso de que um comportamento corrupto envolve a violação de regras estabelecidas em prol do autointeresse e para o ganho e o lucro pessoal, ${ }^{50}$ isto é, que envolve o abuso de poder para obtenção de ganhos privados em prejuízo ao desenvolvimento sustentável, ${ }^{51}$ casos de corrupção passarão a ser desincentivados, reduzidos e reprimidos, o que se iniciará com um sistema normativo eficaz e uma cultura institucional aderente, comprometida com a efetivação dos Objetivos de Desenvolvimento Sustentável da ONU. É dizer, ao se reconhecer que a luta contra a corrupção é um processo e que a mesma não será eliminada de forma instantânea, necessário iniciar um processo cultural de mudança de abordagem, "the cultural approach of individuals starting with simple, clear norms of conduct", o que demandará mobilização de diversas forças da sociedade, direcionando-a para a construção de um "sistema de integridade pública coerente e abrangente" ${ }^{52}$

48 UNODC, 2015, p. 5.

49 Tradução literal de "A cultural approach, therefore, through which the "costs" of corruption are visible and there is an awareness of the reprehensible extent of the offences involved." PARISI, 2019, p. 436.

50 Tradução literal de: "What, then, is "corrupt" behavior? Corruption involves the violation of established rules for personal gain and profit." SEN, 2000, p. 275.

51 Tradução literal do conceito de corrupção elaborado pela Transparência internacional: "corruption is the abuse of an entrusted power for private gain." Disponível em: <https://www.transparency.org/what-iscorruption\#define>. Acesso em: 12 dez. 2019.

52 PARISI, 2019, p. 414 e 439. 


\section{A Agenda 2030 da ONU e os Objetivos de Desenvolvimento Sustentável (ODSs)}

Antes dos Objetivos de Desenvolvimento Sustentável serem estatuídos em 2015, nos anos 2000 foram criados os Objetivos de Desenvolvimento do Milênio - ODMs, também conhecidos como os 8 jeitos de mudar o mundo. O ideal proposto com esses objetivos era de que os Estados membros da ONU pudessem alcançar, em 15 anos, um modelo de desenvolvimento pautado em objetivos capazes de tornar o mundo um lugar mais justo, solidário e melhor para se viver. ${ }^{53}$ Os valores fundamentais, reconhecidos como essenciais para as relações no século XXI e que embasaram os Objetivos de Desenvolvimento do Milênio, foram a liberdade, igualdade, solidariedade, tolerância, respeito pela natureza e responsabilidade comum. Da mesma forma, reconheceu-se a responsabilidade de assegurar a nível mundial os princípios da dignidade da pessoa humana, da igualdade e da equidade. ${ }^{54}$ A partir desses valores e princípios, portanto, foram instituídos os 8 objetivos para mudar o mundo, conforme destacados a seguir: 1. Erradicar a pobreza extrema e a fome; 2 . Atingir o ensino básico fundamental; 3. Promover a igualdade de gênero e autonomia das mulheres; 4 . Reduzir a mortalidade infantil; 5. Melhorar a saúde materna; 6. Combater o HIV/ AIDS, a malária e outras doenças; 7. Garantir a sustentabilidade ambiental; 8. Estabelecer uma parceria mundial para o desenvolvimento.

53 GARCIA; GARCIA, 2016, p. 196.

54 UNDP. Declaração do Milênio. Nova Iorque, 6-8 de setembro de 2000. Disponível em: <https://www.br.undp.org/content/brazil/pt/home/ library/ods/declaracao-do-milenio.html>. Acesso em: 29 jan. 2020. p. 1, 3 e 4 . 
Em 2015, após a realização de um balanço em relação ao atingimento dos objetivos acima propostos, constatou-se muitos progressos e avanços, como a redução da pobreza global, diminuição da mortalidade infantil, aumento do acesso à água potável e diminuição de doenças infecciosas. Ocorre que muitas lacunas também foram deixadas, e o relatório dos ODMs de 2015 destacou que, apesar do sucesso em algumas áreas, os indivíduos mais pobres e mais vulneráveis estavam sendo deixados para trás, tendo em vista a persistência da desigualdade de gênero; do elevado desnível social entre os mais pobres e mais ricos; das alterações climáticas e da degradação ambiental em prejuízo ao progresso alcançado, que afetam de forma mais gravosa a população mais pobre; dos conflitos que constituem o maior problema no desenvolvimento humano; e das milhões de pessoas que ainda vivem na extrema pobreza e com fome e sem acesso a serviços básicos. ${ }^{55}$

Diante desse cenário, ainda em 2015, foi estabelecida a Agenda 2030 da ONU para o desenvolvimento sustentável, instituindo-se 17 novos objetivos, subdivididos em 169 metas, cujo fundamento principal é não deixar ninguém para trás: "as we embark on this collective journey, we pledge that no one will be left behind" ${ }^{56}$ Nesse sentido, os objetivos e metas da Agenda 2030 possuem três pilares básicos: acabar com a pobreza, proteger o planeta e garantir a prosperidade para todos como parte de um novo desenvolvimento sustentável. ${ }^{57}$ Segundo o Preâmbulo da Agenda 2030, a iniciativa se trata

55 ONU. The Millennium Development Goals Report 2015. Disponível em: <https://www.un.org/millenniumgoals/2015_MDG_Report/pdf/ MDG\%202015\%20rev\%20(July\%201).pdf>. Acesso em: 29 jan. 2020.

56 ONU. Transforming our world: the 2030 Agenda for Sustainable Development. Preamble. Disponível em: <https://sustainabledevelopment. un.org/post2015/transformingourworld>. Acesso em: 29 jan. 2020.

57 GARCIA; GARCIA, 2016, p. 202. 
de um plano de ação para as pessoas, para o planeta e para a prosperidade, buscando fortalecer a paz universal com mais liberdade. ${ }^{58}$ Daí se comprova a necessidade do engajamento dos países em uma proposta de desenvolvimento sustentável que se preocupe com as gerações presentes e futuras. ${ }^{59}$

Dada a delimitação do tema aqui proposto, isto é, do estudo dos impactos do combate à corrupção para a efetivação da Agenda 2030 da ONU, destaque-se que a análise ficará adstrita ao Objetivo de Desenvolvimento Sustentável 16 , especialmente no que diz respeito à meta 16.5 , bem como aos impactos de sua efetivação aos demais ODSs.

O ODS 16 disciplina sobre paz, justiça e instituições eficazes, instituindo como objetivo a promoção de sociedades pacíficas e inclusivas para o desenvolvimento sustentável, proporcionando o acesso à justiça para todos e construindo instituições eficazes, responsáveis e inclusivas em todos os níveis. A meta 16.5, relacionada diretamente à construção de instituições eficazes, almeja a redução substancial da corrupção e do suborno em todas as suas formas. Nesse ponto afirma-se a relação direta entre ambos os institutos visto que a construção de instituições eficazes depende da confiança depositada nas mesmas, o que, conforme já destacado, decorre da compatibilidade de sua existência prática com os objetivos aos quais foi criada. ${ }^{60}$ Assim, se em um ambiente imerso na cultura da corrupção não há espaço para exis-

58 ONU. Transformando nosso mundo: a Agenda 2030 para o desenvolvimento sustentável. Disponível em: <https://nacoesunidas.org/wp-content/ uploads/2015/10/agenda2030-pt-br.pdf>. Acesso em: 29 jan. 2020.

59 Nesse sentido, Juarez Freitas, discorrendo sobre o conceito de sustentabilidade destaca que se trata de um "princípio constitucional que determina promover o desenvolvimento social, econômico, ambiental, ético e jurídico-político, no intuito de assegurar as condições favoráveis para o bem-estar das gerações presentes e futuras". FREITAS, 2012, p. 50

60 FOCKINK, 2019, p. 184. 
tência de confiança, tampouco haverá para a construção de instituições eficazes. Notável, dessa forma, o engajamento da ONU em prol do combate à corrupção.

Embora os crescentes esforços no combate à corrupção e o aumento de iniciativas como os ODSs, que tem cada vez mais fomentado a implementação de mecanismos aptos a combater à corrupção, buscando o aculturamento da integridade, o aumento da confiança nas instituições e, por conseguinte, o desenvolvimento sustentável, ainda falta vontade política e engajamento de fato em muitos países.

No Brasil, por exemplo, existe um grupo temático específico de anticorrupção que atua no desenvolvimento de metodologias e ferramentas para melhoria de padrões de controles de atos lesivos dentro de empresas e do Poder Público. ${ }^{61}$ Ao mesmo tempo, o financiamento ilegal de partidos políticos e eleições, com o objetivo de servir às vontades e interesses de alguns poucos, faz com que a corrupção integre o sistema político brasileiro. ${ }^{62}$ Nesse sentido, é preciso destacar que o combate à corrupção não é uma batalha de apenas algumas empresas ou entes, órgãos e entidades públicos; a diminuição - e porque não a erradicação - dessas práticas irregulares depende de ações coordenadas de todos os principais atores do desenvolvimento sustentável, isto é, do Estado e da sociedade. ${ }^{63}$ É dizer, a atividade anticorrupção deve envolver uma estrutura estreita entre diferentes autoridades do Estado, inclusive em cooperação intergover-

61 GOTO, 2018, p. 46. Ainda que desde a promulgação da Constituição Federal de 1988 haja suporte jurídico consolidado no país voltado à garantia da moralidade na esfera da Administração Pública. Nesse sentido, cf. TOMAZ; CALDAS, 2018, p. 183.

62 GODINHO, 2001, p. 352.

63 GOTO, 2018, p. 48-49. 
namental, a fim de combater a difusão e os danos causados pela corrupção. ${ }^{64}$

Assim, o primeiro passo para a efetivação do ODS 16 e da meta 16.5 é, justamente, o comprometimento e a vontade política dos governantes e das sociedades desde a criação e implementação de instrumentos para o combate à corrupção, até a sua manutenção e monitoramento contínuo. Isso, porque, considerando a teoria da influência dos valores, existe uma tendência dos demais indivíduos seguirem os exemplos daqueles com quem se relacionam, ${ }^{65}$ já que os comportamentos desses indivíduos são pautados por valores e códigos de condutas prevalecentes na sociedade e nas organizações em que estão inseridos. Assim, a mudança de uma cultura da corrupção para uma cultura da integridade, pautada na lealdade e na transparência, e, por conseguinte, mais propensa à expansão da liberdade instrumental da garantia de transparência, fundada, justamente, na confiança dos indivíduos, deve ocorrer, necessariamente, com o apoio daqueles que detêm o poder sobre a cultura institucional da sociedade como um todo.

Não sem razão, um dos maiores riscos às economias emergentes é a falta de um modelo de conduta ética endossado pelos governantes, aliado às incompatibilidades no comportamento e no discurso. ${ }^{66}$ A corrupção, nesse sentido, tem um custo sociopolítico: a queda da legitimidade e da credibilidade das ações conduzidas pelo poder público. ${ }^{67}$ Para evitar esse custo, portanto, é necessário um alinhamento

64 Tradução literal de "Anti-corruption activity, therefore, involves a framework of close consultation between different State authorities, at the many levels involved, in the context of intergovernmental cooperation in order to contain its diffusion and combat the damage it causes." PARISI, 2019, p. 400.

65 ZENKNER, 2019, p. 373.

66 CLAYTON, 2013, p. 152.

67 GODINHO, 2001, p. 354. 
daquilo que se fala com o que se faz, de modo que, quando as ações e os comportamentos do grupo não estão em concordância, há uma brecha de autenticidade e integridade e não há base para confiança. ${ }^{68}$ Assim, é o comprometimento de fato - e não apenas no discurso - com a Agenda 2030 que permitirá uma mudança de cultura que penetre na própria essência da sociedade, interferindo nos seus hábitos, costumes, valores, práticas e processos. ${ }^{69}$ Se não, a ausência de comprometimento de fato é o que resulta, por exemplo, a permanente queda do Brasil no ranking da Transparência Internacional. ${ }^{70}$

A percepção que se tem, nesse sentido, é que, a ausência de combate efetivo à corrupção demonstra a falta de compromisso efetivo com a Agenda 2030 e com as demais iniciativas que buscam combater internacionalmente a corrupção, como a ratificação de tratados internacionais, a publicação de leis anticorrupção e a implementação de metodologias para aderência de Programas de Integridade e Compliance no Poder Público e na iniciativa privada. Ocorre, conforme analisado, que a corrupção é uma das barreiras mais severas ao desenvolvimento como liberdade. Assim, partindo da premissa de que o desenvolvimento em termos teóricos é

68 Tradução literal de: "We call this alignment between what we say and what we do "walking the talk" because as outside observers the only way we know what is going on internally in others is what they tell us. If the actions and behaviors of individuals or groups are in alignment with the values and beliefs that they tell us they espouse, then we consider this person or group to operate with authenticity or integrity. When the actions and behaviors of individuals or groups are not in concordance, there is a lack of authenticity and integrity and there is no foundation for trust." BARRETT, 2006, p. 107.

69 ZENKNER, 2019, p. 375.

70 TRANSPARÊNCIA INTERNACIONAL. Índice de percepção da corrupção 2019. Disponível em: <https://ipc.transparenciainternacional.org.br/?gcl id=EAIaIQobChMIipe_8pm95wIVxwiRCh09WQV-EAAYASAAEgL9jPD_ BwE>. Acesso em: 29 jan. 2020. 
um processo e em termos jurídicos um direito, tendo como núcleo essencial os direitos individuais e sociais, e como fim assegurar a expansão de capacidades de maneira a permitir o gozo da liberdade substantiva, ${ }^{71}$ o combate à corrupção deve ser considerado núcleo essencial do desenvolvimento, e, portanto, um dever do Estado e da sociedade.

\section{Os impactos do combate à corrupção no Brasil para 0 atingimento dos ODSs}

Segundo Maria Coeli Simões Pires, ${ }^{72}$ até os anos 30 o planejamento voltado ao desenvolvimento privilegiava apenas a infraestrutura estratégica. A partir desse período, com o nacional populismo, o Brasil se voltou a planos direcionados para infraestrutura de base, investindo em bens de capital. Já nos anos 50, o planejamento estatal tinha como foco a diversificação da indústria e o desenvolvimento nacional. No período da ditadura militar, por sua vez, o Brasil passou a ter forte preocupação com o crescimento econômico. Foi somente na década de 80, então, que se registrou o esgotamento da estratégia desenvolvimentista e do autoritarismo militar, sucedendo-se as tentativas de redemocratização. ${ }^{73}$

Diante desse brevíssimo contorno fático a respeito do direcionamento do desenvolvimento no Brasil, pode-se dizer que, até a promulgação da Constituição da República de 1988, buscava-se um capitalismo desenvolvimentista que se preocupava exclusivamente com o crescimento econômico. Após o período do regime militar, e com a promulgação da Constituição da República de 1988, portanto, o Brasil alterou esse cenário, passando a adotar um modelo de Estado

\footnotetext{
71 SCHIER, 2019, p. 64-65.

72 PIRES, 2010, p. 176-177.

73 BERCOVICI, 2004, p 24.
} 
Social e Democrático de Direito. ${ }^{74}$ Assim, já em seu preâmbulo, a Constituição da República de 1988 institui que o Estado Democrático deverá assegurar o desenvolvimento de forma ampla. ${ }^{75}$ Não sem razão, os objetivos previstos em seu artigo $3^{\circ}$ - que impõem ao Estado brasileiro a edificação de uma sociedade livre, justa e solidária; erradicando a pobreza e reduzindo as desigualdades sociais e regionais; e promovendo o bem de toda a população - plasmaram no texto constitucional um modelo de sociedade compatível com o Relatório de Desenvolvimento Humano de 2016 da ONU: pobreza e fome erradicadas; dignidade e igualdade devem prevalecer; garantia de vida próspera e plena para todos; sociedades sejam pacíficas, justas e inclusivas; e onde se viva em harmonia com a natureza. ${ }^{76}$

Como se pode notar, a Constituição da República de 1988 trouxe uma nova percepção da ideia de desenvolvimento, considerando-o um valor supremo e objetivo fundamental, ladeado pelo bem-estar, pela igualdade e pela justiça. Vê-se, portanto, uma ideia intimamente vinculada ao valor da igualdade, cujo intuito é reduzir as distâncias entre as posições existentes na sociedade, diminuindo-se as desigualdades entre os cidadãos. ${ }^{77}$ Assim, sendo o desenvolvimento em termos jurídicos um direito, e tendo como núcleo essencial os direitos individuais e sociais, assegurando a expansão de capacidades e permitindo o gozo da liberdade substantiva, não há como garantir tal instituto sem as garantias de transparência propostas por Amartya Sen, tampouco sem efetivar o combate à corrupção previsto na meta 16.5 da Agenda 2030 da ONU.

\footnotetext{
74 SCHIER, 2019, p. 27.

75 SCHIER, 2019, p. 71.

76 SCHIER, 2019, p. 27 e 38.

77 HACHEM, 2013, p. 150.
} 
Nesse sentido, Marcelo Zenkner, citando a conferência do Professor Jorge Miranda na Faculdade de Direito da Universidade de Lisboa, destacou que a existência de uma administração pública transparente, não corrupta e eficiente é requisito imprescindível para efetivação de direitos sociais. ${ }^{78}$ Daí, portanto, se falar na importância da efetivação da liberdade instrumental de garantia de transparência de Amartya Sen para atingir o desenvolvimento nacional sustentável.

A corrupção corrói os direitos fundamentais e prejudica àqueles que mais dependem do Poder Público. É dizer, ela afeta de forma mais acentuada aqueles economicamente mais frágeis, uma vez que os recursos públicos que deveriam ser alocados de forma a suprir suas carências são desviados para finalidades escusas. ${ }^{79}$ Nesses termos, quanto maior o prejuízo ao erário decorrente da corrupção, maior o prejuízo aos serviços e utilidades públicas e, por conseguinte, aos direitos fundamentais dos usuários que poderiam ser tutelados com aqueles recursos. ${ }^{80}$

O alto custo gerado pela corrupção enfraquece a economia e aumenta a instabilidade política e as desigualdades sociais, sendo, sem dúvida, uma das maiores barreiras ao desenvolvimento. É que a corrupção atinge a própria manutenção do Estado Democrático de Direito. Assim, existindo uma Administração Pública que tende a ser corrupta, haverá, por consequência, prejuízo aos bens e serviços públicos. Nesse sentido, bem destaca Caroline Fockink ser fundamental a confiança do cidadão nas instituições públicas, "como um requisito preponderante para o bom e legítimo funcionamento da democracia", isto é, como "um produto de primeira necessidade desde o começo da histó-

78 ZENKNER, 2019, p. 85.

79 FORTINI; MOTTA, 2016, p. 94.

80 ZENKNER, 2019, p. 86. 
ria humana". Do contrário, isto é, "quando as instituições despertam desconfiança", é justamente nesta etapa que a corrupção assume um protagonismo enorme. ${ }^{81}$ Daí, então, a importância do fortalecimento de instrumentos aptos a monitorar, desincentivar, controlar, reduzir e reprimir essas condutas, que apenas acarretam prejuízos à economia, agravam as desigualdades sociais e impedem o adequado desenvolvimento econômico-social e sustentável..$^{82}$ Isto é, daí a relevância de um "poder intelectual" como mecanismo de influência do pensamento, ${ }^{83}$ no sentido de alterar o status quo de uma sociedade corrupta para uma sociedade pautada pela conformidade, ética, integridade e transparência.

Insiste-se, a corrupção não apenas é responsável pelo desvio de recursos públicos, mas afeta, ainda, negativamente a qualidade de serviços básicos como saúde, segurança e educação, impactando diretamente o atendimento dos Objetivos de Desenvolvimento Sustentável da ONU, e, por conseguinte, no próprio desenvolvimento sustentável de países emergentes ${ }^{84}$ Pode-se dizer, portanto, que o não atendimento da meta 16.5 implica o não atendimento de outros ODSs, como os objetivos 3, 4 e 9, por exemplo. Isso porque os escândalos relacionados a desvios na área da saúde impedem a promoção de uma vida saudável e de bem-estar para todos, em todas as idades (Objetivo 3. Assegurar uma vida saudável e promover o bem-estar para todos, em todas as idades). Da mesma forma, a locomoção a pé para a escola e a ausência de merenda escolar adequada para as crianças impedem a garantia da educação inclusiva, equitativa e de qualidade, bem como da promoção das oportunidades de aprendizagem ao longo da vida para todos (Objetivo 4. Assegurar a educação

81 FOCKINK, 2019, p. 189-191.

82 MOREIRA NETO; FREITAS, 2014.

83 Sobre o tema cf. ZIMBICO, 2020, p. 348.

84 GOTO, 2018, p. 47 
inclusiva e equitativa e de qualidade, e promover oportunidades de aprendizagem ao longo da vida para todos). O mesmo ocorre com o desvio de recursos que poderiam ser aplicados em demandas de infraestrutura, impedindo-se a construção de infraestruturas resilientes, a promoção da industrialização inclusiva e sustentável e o fomento da inovação (Objetivo 9. Construir infraestruturas resilientes, promover a industrialização inclusiva e sustentável e fomentar a inovação).

Diante da inegável correlação entre os desvios de recurso públicos, a violação de direitos fundamentais e, por conseguinte, da efetivação da Agenda 2030 da ONU, é necessário considerar como direito aquele de viver em uma sociedade livre de corrupção. ${ }^{85}$ É que, como asseveram Matthew Murray e Andrew Spalding, ${ }^{86}$ é impossível tratar de outros direitos fundamentais, como saúde e educação, por exemplo, para utilizar as implicações dos ODSs 3 e 4, sem tratar do combate à corrupção disciplinado na meta 16.5. Assim, se a prevenção à corrupção é uma pré-condição essencial para o atingimento dos Objetivos de Desenvolvimento Sustentável em sua integralidade, os indivíduos devem ter o direito de esperar que o governo seja honesto e responsável. Dessa forma, a compreensão da corrupção como uma forma de violação de direitos concebe uma mensagem tanto às vítimas da corrupção, quanto aos seus coatores, isto é, que a aplicação vigorosa de medidas anticorrupção não é apenas possível, mas essencial para assegurar os demais direitos fundamentais explícitos e implícitos, ${ }^{87}$ condição de

85 ZENKNER, 2019, p. 87 e 92.

86 Tradução literal de "A freedom from corruption would have an essential role in upholding and enforcing other human rights." MURRAY; SPALDING, 2016, p. 06.

87 Tradução literal de "Reframing corruption as a rights violation sends an unequivocal message to both the victims of official corruption and the perpetrators: that corruption is neither cultural nor human nature; that the state might violate that right but cannot take it away; and that the 
consolidação do desenvolvimento nacional sustentável.

\section{Conclusão}

A corrupção não é um fenômeno recente, tampouco o são as propostas de seu combate. ${ }^{88}$ Contudo, a falta de confiança, de integridade e de transparência no âmbito das instituições, certamente, são o maior obstáculo à garantia da efetividade dos Objetivos de Desenvolvimento Sustentáveis.

Assim, os impactos reputacionais gerados em razão dos escândalos bilionários de corrupção, ${ }^{89}$ que implicaram prejuízos de elevada monta tanto ao Poder Público quanto às empresas privadas, mobilizaram a busca por instrumentos de reforma institucional em prol da prevenção e combate à corrupção. ${ }^{90}$ É que, conforme analisado, a corrupção afeta de forma mais acentuada aqueles economicamente mais frágeis, pois os recursos públicos, que deveriam ser alocados de forma a suprir suas carências, são desviados mediante condutas ilegais, ilícitas e ilegítimas. Assim, quanto maior o prejuízo ao erário decorrente da corrupção, maior o prejuízo aos serviços e utilidades públicas e, por conseguinte, aos direitos fundamentais dos usuários que poderiam ser

vigorous enforcement of anti-corruption measures is not only possible, but essential." MURRAY; SPALDING, 2016, p. 15.

88 Tradução literal de "Corruption is not, however, a new phenomenon, nor are proposals for dealing with it." Sen, 2000, p. 275. Sobre o tema, cf. ainda PARISI, 2019, p. 439.

89 A JBS, por exemplo, teve uma perda de 3,5 bilhões de reais após a assinatura da delação dos responsáveis pela Holding J e F. Disponível em: <https:// brasil.elpais.com/brasil/2017/05/27/economia/1495837922_279258.html>. Acesso em: 23/03/2020. Da mesma forma, a Petrobras contou com prejuízo de mais de 21 bilhões de reais. Disponível em: <https://economia.uol.com. br/reportagens-especiais/apos-anos-de-crise-petrobras-se-recupera-e-dalucro/\#tematico-1:>. Acesso em: 23/03/2020.

90 BERTOCCELLI, 2019, p. 51. 
tutelados com aqueles recursos. ${ }^{91}$

Diante do cenário apresentado, não há dúvidas de que a corrupção afeta toda a cadeia de desenvolvimento sustentável de um país, sendo necessário que o combate seja reconhecido como um dever do Estado e da sociedade. Nesse sentido, deve-se salvaguardar o direito dos indivíduos de viver em uma sociedade livre de corrupção, criando-se uma espécie de "poder intelectual" como mecanismo de influência de condutas. ${ }^{92}$ Assim, o combate à corrupção previsto na meta 16.5 permitirá a efetivação e cumprimento dos demais Objetivos de Desenvolvimento Sustentável, visto que a atuação íntegra, penetrando na essência da sociedade, interferindo nos seus hábitos, costumes, valores, práticas e processos, altera a cultura corrupta - diminuindo-se o desvio de recursos - para uma prática da ética, integridade e transparência, permitindo melhoria na alocação do dinheiro público e na qualidade dos serviços prestados, e, por conseguinte, direcionando o Brasil ao desenvolvimento nacional sustentável.

Dessa forma, se os indivíduos de uma sociedade tendem a exercer comportamentos repetitivos, havendo uma mudança de comportamento em sentido inverso de comportamentos pautados pela corrupção, haverá uma transformação desse círculo vicioso em um virtuoso. E esse círculo virtuoso permitirá a existência de maior confiança na relação entre os indivíduos de uma organização ou de uma sociedade, possibilitando também a interação destes com o governo, o que, por conseguinte, resguardará a garantia de transparência e da liberdade instrumental reconhecida por Amartya Sen, combatendo-se, assim, uma das mais graves barreiras no caminho do desenvolvimento: a corrupção.

\footnotetext{
91 ZENKNER, 2019, p. 86.

92 ZIMBICO, 2020, p. 348.
} 


\section{Referências:}

ALMEIDA, Alberto Carlos. A cabeça do brasileiro. São Paulo: Record, 2007.

BARRETT, Richard. Building a values-driven organization: a whole system approach to cultural transformation. Oxford: Elsevier, 2006. Disponível em: <http://shora. tabriz.ir/Uploads/83/cms/user/File/657/E_Book/Economics/Building\%20a\%20Values-Driven.pdf>. Acesso em: 12/12/2019.

BERCOVICI, Gilberto. O estado desenvolvimentista e seus impasses: uma análise do caso brasileiro. Coimbra: Coimbra, 2004.

BERTOCCELLI, Rodrigo de Pinho. Compliance. In. CARVALHO, André Castro; ALVIM, Tiago Cripa; BERTOCCELLI, Rodrigo de Pinho; VENTURINI, Otávio (Coord.). Manual de Compliance. Rio de Janeiro: Forense, 2019.

BOBBIO, Norberto; MATTEUCCI, Nicola; PASQUINO, Gianfranco. Dicionário de Política. 5. ed. Brasília: Universidade de Brasília, 2000.

CANETTI, Rafaela; MENDONÇA, José. Corrupção para além da punição: aportes da economia comportamental. Revista de Direito Econômico e Socioambiental, Curitiba, v. 10, n. 1, p. 104-125, jan./abr. 2019. DOI: 10.7213/rev.dir. econ.soc.v10i1.19003.

CLAYTON, Mona. Entendendo os desafios de Compliance no Brasil: um olhar estrangeiro sobre a evolução do compliance anticorrupção em um país emergente. In. DEBBIO, Alessandra Del; MAEDA, Bruno Carneiro; AYRES, Carlos Henrique (Coord.). Temas de Anticorrupção e Compliance. Rio de Janeiro: Elsevier, 2013. 
COLAPINTO, Filippo. Il sistema della prevenzione della corruzione in Italia. Revista Brasileira de Estudos Políticos, Belo Horizonte, n. 118, pp. 207-244, jan./jun. 2019.

COSTA, Helena Regina Lobo da. Corrupção na História do Brasil: reflexões sobre sua origem no período colonial. In. DEBBIO, Alessandra Del; MAEDA, Bruno Carneiro; AYRES, Carlos Henrique (Coord.). Temas de Anticorrupção e Compliance. Rio de Janeiro: Elsevier, 2013.

CUNHA, Daniele Estivalete; MOURA, Gilnei Luiz de 2; RIZZETTI, Daniele Medianeira; TEIXEIRA, Emidio Gressler. A influência dos valores organizacionais no comportamento estratégico: Um estudo das empresas do setor hoteleiro da região turística das Hortênsias/RS. Espacios, vol. 37, n. 28, a. 2016. Disponível em: <https://www.revistaespacios. com/a16v37n28/16372819.html>. Acesso em: 12/12/2019.

FOCKINK, Caroline. Os efeitos negativos da corrupção nas instituições públicas e no regime democrático. Revista de Direitos Fundamentais \&. Democracia, Curitiba, v. 24, n. 3, p. 181-210, set./dez. 2019. p. 191. DOI: 10.25192/issn.19820496.rdfd.v24i31331.

FORTINI, Cristiana; MOTTA, Fabrício. Corrupção nas licitações e contratações públicas: sinais de alerta segundo a Transparência Internacional. A\&C - Revista de Direito Administrativo \& Constitucional, Belo Horizonte, a. 16, n. 64, p. 93-113, abr./jun., 2016.

FREITAS, Juarez. Sustentabilidade: direito ao futuro. 2. ed. Belo Horizonte: Fórum, 2012.

GARCIA, Denise Schmitt Siqueira; GARCIA, Heloise Siqueira. Objetivos de Desenvolvimento do Milênio e as novas perspectivas do desenvolvimento sustentável pela Organização das Nações Unidas. Revista da Faculdade de 
Direito da UFRGS, Porto Alegre, n. 35 , vol. esp., p. 192 206, dez., 2016.

GODINHO, Thiago José Zanini. Contribuições do direito internacional ao combate à corrupção. Revista da Faculdade de Direito da Universidade Federal de Minas Gerais, Belo Horizonte, n. 58, p. 347- 386, jan./jun., 2001.

GOTO, Reynaldo. O combate à corrupção sob a ótica dos objetivos de desenvolvimento sustentável. In: PAULA, Marco Aurelio Borges de; CASTRO, Rodrigo Pironti Aguirre de. (Coord.). Compliance, gestão de riscos e combate à corrupção: integridade para o desenvolvimento. Belo Horizonte: Fórum, 2018.

HACHEM, Daniel Wunder. A noção constitucional de desenvolvimento para além do viés econômico: reflexos sobre algumas tendências do Direito Público brasileiro. Revista de Direito Administrativo \& Constitucional - A\&C, Belo Horizonte, a. 13, n. 53, p. 133-168, jul./set., 2013.

HOLANDA, Sérgio Buarque de. Raízes do Brasil. 26. ed., São Paulo: Companhia das Letras, 1995.

MOREIRA NETO, Diogo de Figueiredo; FREITAS, Rafael Véras de. A juridicidade da Lei Anticorrupção: reflexões e interpretações prospectivas. Disponível em: http://www. editoraforum.com.br/wp-content/uploads/2014/01/ART_ Diogo-Figueiredo-Moreira-Neto-et-al_Lei-Anticorrupcao. pdf>. Acesso em: 12/12/2019.

MURRAY, Matthew; SPALDING, Andrew. Freedom from Official Corruption as a Human Right. Disponível em: <https://www.brookings.edu/wp-content/uploads/2016/06/Murray-and-Spalding_v06.pdf>. Acesso em: $29 / 01 / 2020$. 
ONU. The Millennium Development Goals Report 2015. Disponível em: <https://www.un.org/millenniumgoals /2015_MDG_Report/pdf/MDG\%202015\%20rev\% 20 (July\%201).pdf>. Acesso em: 29/01/2020.

ONU. Transformando nosso mundo: a Agenda 2030 para o desenvolvimento sustentável. Disponível em: <https:/ / nacoesunidas.org/wp-content/uploads/2015/10/agenda2030-pt-br.pdf>. Acesso em: 29/01/2020.

ONU. Transforming our world: the 2030 Agenda for Sustainable Development. Preamble. Disponível em: <https:/ / sustainabledevelopment.un.org/post2015/transformingourworld>. Acesso em: 29/01/2020.

PARISI, Nicoletta. The institutionalisation of strategies to prevent corruption: the international and European model. Revista Brasileira de Estudos Políticos, Belo Horizonte, n. 119, pp. 397-447, jul./ dez. 2019.

PIRES, Maria Coeli Simões. Esgotamento do modelo de desenvolvimento excludente no Brasil e a ressemantização das atividades de planejamento e articulação governamentais à luz do paradigma democrático. In: Modesto, Paulo (Org.) Nova organização administrativa brasileira. Belo Horizonte: Fórum, 2010.

PLATÃO. A República. Trad. Pietro Nassetti. São Paulo: Martin Claret, 2006.

RAVLIN, Elizabeth. Valores. In. COOPER, Cary L; ARGYRIS, Chris (Orgs). Dicionário enciclopédico de administração. São Paulo: Atlas, 2003.

RESENDE, André Lara. Corrupção e capital cívico. Valor Econômico, São Paulo, 31 jul. 2015.

ROSENN, Keith S. O Jeito na cultura jurídica brasileira. Rio de Janeiro, Renovar: 1998. 
SCHIER, Adriana da Costa Ricardo. Fomento: administração pública, direitos fundamentais e desenvolvimento. Curitiba: Íthala, 2019.

SEN, Amartya Kumar. Development as Freedom. 4. reimp. Oxford: Oxford University Press, 2000.

SODRÉ, Flavius Raymundo Arruda. Os impactos da corrupção no desenvolvimento humano, desigualdade de renda e pobreza dos municípios brasileiros. 2014. 48 fls. Dissertação (Mestrado em Economia) - Universidade Federal de Pernambuco, CCSA, 2014.

SMITH, Adam. The theory of moral sentiments. 6. ed. 1970. p. 143. Disponível em: <https://www.ibiblio.org/ ml/libri/s/SmithA_MoralSentiments_p.pdf>. Acesso em: 12/12/2019.

TOMAZ, Carlos Alberto Simões de; CALDAS, Roberto Correia da Silva Gomes. A cooriginariedade entre o direito e a moral e a conformação da moralidade administrativa no sistema jurídico brasileiro. Revista Brasileira de Estudos Políticos, Belo Horizonte, n. 117, pp. 159-191, jul./ dez. 2018.

TRANSPARENCIA INTERNACIONAL. What is corruption. Disponível em: <https://www.transparency.org/ what-is-corruption\#define>. Acesso em: 12/12/2019.

TRANSPARÊNCIA INTERNACIONAL. Índice de percepção da corrupção 2019. Disponível em: <https:/ /ipc. transparenciainternacional.org.br/?gclid=EAIaIQobChMIip e_8pm95wIVxwiRCh09WQV-EAAYASAAEgL9jPD_BwE>. Acesso em: 29/01/2020.

UNODC. Corrupção e Desenvolvimento. Disponível em: <https://www.unodc.org/documents/lpo-brazil/Topics_corruption/Campanha-2013/CORRUPCAO_E_DESENVOLVIMENTO.pdf>. Acesso em: 23/3/2020. 
UNDP. Declaração do Milênio. Nova Iorque, 6-8 de setembro de 2000. Disponível em: <https://www.br.undp. org/content/brazil/pt/home/library/ods/declaracao-do-milenio.html>. Acesso em: 29/01/2020.

ZANON, Patricie Barricelli; GERCWOLF, Susana. Programas de Compliance e incentivos no combate à corrupção no Brasil. NOHARA, Irene Patrícia ; PEREIRA, Fábio Bastos. (coord). Governança, Compliance e Cidadania. 2. ed. rev., atual. e ampl. São Paulo: Thomson Reuters Brasil, 2019.

ZENKNER, Marcelo. Integridade governamental e empresarial: um espectro da repressão e da prevenção à corrupção no Brasil e em Portugal. Belo Horizonte: Fórum, 2019.

ZIMBICO, Octavio Jose. O Estado e a Sociedade Civil: uma relação histórica baseada no exercício do poder? Revista Brasileira de Estudos Políticos, Belo Horizonte, n. 120, pp. 341-368, jan./jun. 2020.

O artigo foi produzido a partir da discussão nas aulas da disciplina Administração Pública e Democracia, do PPGD da Unibrasil, ministrada pela coautora Professora Doutora Adriana Schier, com coleta e processamento de dados a partir das obras indicadas na bibliografia. A análise e a elaboração do texto final foram feitas em conjunto, mediante revisões colaborativas. (Texto informado pelos autores) 
Recebido em 30/03/2020

Aprovado em 22/07/2020

Adriana da Costa Ricardo Schier

E-mail: adrianacrschier@uol.com.br
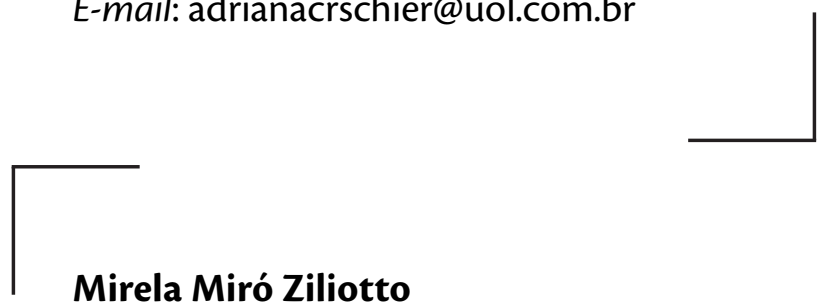

Mirela Miró Ziliotto

E-mail:mirela@pirontiadvogados.com 